\title{
Analysis of the Cruciform Sample Shapes for Bi-Axial Tensile Tests Based on the Geometries Currently Present in the Literature
}

\author{
Grzegorz Mitukiewicz ${ }^{*}$, Cezary Kuzalski', Jaroslaw Goszczak', \\ Jacek Leyko', Zlatina Dimitrova², Damian Batory ${ }^{1}$ \\ 1 Department of Vehicles and Fundamentals of Machine Design, Faculty of Mechanical Engineering, Lodz \\ University of Technology, ul. Żeromskiego 116, 90-924 Łódz, Poland \\ 2 PSA Groupe, Centre Technique de Velizy Route de Gisy, Parc Innovel Sud, 78943, Velizy-Villacoublay Cedex, \\ France \\ *Corresponding author's email: grzegorz.mitukiewicz@p.lodz.pl
}

\begin{abstract}
The paper contributes to the global research of the best shape of cruciform samples for biaxial tensile tests. Based on literature research, one of the proposed samples' shape comparison methodology was employed to achieve the ultimate results. A variety of specimens with different shapes were compared and modelled with the use of Finite Element Method (FEM). Afterwards, five the most promising sample shapes were examined on a tests stand to validate the simulation results. Based on the obtained research results a new parameter defining the ability of the cruciform sample to reach the possible achievable strain in the centre area, was introduced. The obtained data shows, that sample with the highest Relative Cost Function parameter (RCF) presented the highest strain in the gauge region and the sample with the lowest RCF reached the lowest strain in the center. The rest of the samples remained within the general trend showing a compatibility between the RCF parameter and the obtained strain.
\end{abstract}

Keywords: cruciform sample; forming limit diagram; bi-axial tensile test.

\section{INTRODUCTION}

Currently, the sheet metal parts are used in most of the branches of industry, such as automotive, aerospace, household appliances, electronics, industrial machines, heavy duty machines etc., mainly for chassis and cases. For manufacturing of sheet metal parts there are many forming processes that can be used like: bending, deep drawing, hydroforming, roll forming, stretch forming or spinning, but two are the most common, namely: bending with deep drawing and the stamping. In order to reduce the cost of production, the manufacturers strive to reduce material consumption. Expensive test rigs are replaced by cheaper and faster numerical simulations. However, the optimization of the element design and the process of its forming, using numerical simulation requires knowledge of the material behaviour subjected to the specific load. Therefore researchers create a database in the form of, for example, Forming Limit Diagram (FLD) for the material $[1 \div 3]$.

Currently, determination of FLD requires time-consuming and labour-intensive experimental research. In practice, two types of tests are used (Fig. 1):

- out of plane stretching- Nakazima et al. [4] and Hecker et al. [5];

- in plane stretching - Marciniak et al. [6].

To induce a plastic deformation in the sample, both of these methods use piston which deforms the sample in a direction perpendicular to its plane. In Nakazima method (Fig. 1a), the sample forms a dome with a curvature of the spherical piston. In Marciniak-Kuczyński method (Fig. 2b) because of the special shape of the piston, the measuring area of the sample remains flat. Drawbacks of these methods are primarily a multitude of sample shapes that are needed to be loaded and 

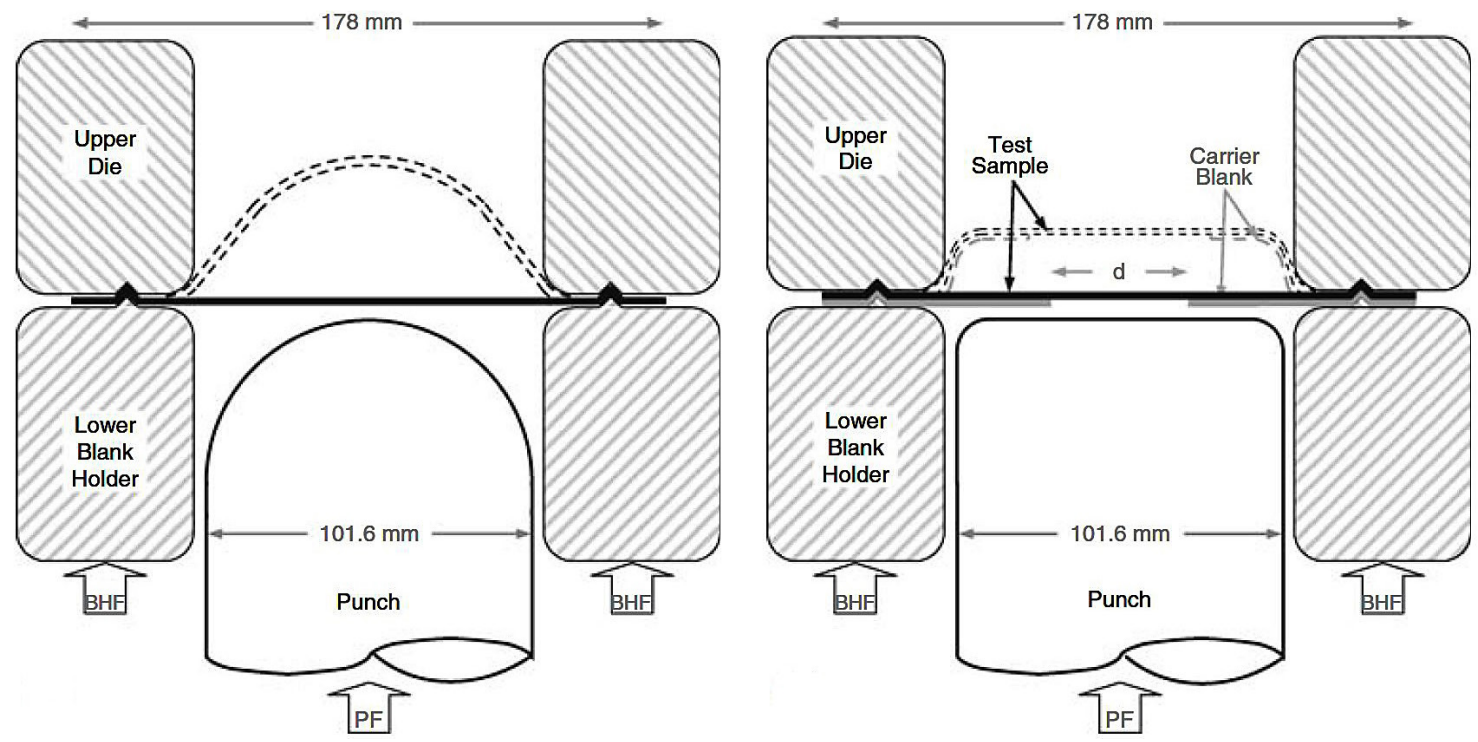

Fig. 1. FLD tests: a) Nakazima setup, b) Marciniak-Kuczyński setup [7]

friction between the sample and the piston, which has an influence on the results. Moreover, the deformations of the plate in mutually perpendicular directions, caused by the piston pressure, are geometrically connected to each other.

Another promising method for determining the FLD of a material is the employment of crossshaped samples. Leotoing et al. [8] have shown that the superiority of this solution lies in the fact that the strain path in the gauge region can be realized by controlling each arm separately using only one specimen geometry. Since the tested area of the material is suspended in space, the formability can be studied without an additional friction which can influence the results. The correct shape of the sample is essential to achieve a high level of relative strains in the central region of the sample.

One of the methods to decrease the strength in the centre of the sample is thinning by milling the material from one or both sides of the specimen. Shao at al. [9] have developed the cruciform sample for FLDs under hot stamping conditions. The influence of thickness minimisation in the gauge area and slots in the arms of the sample were optimized to enhance the strain in the centre. Fracture in the desired area under the biaxial tensile loading was obtained by the appropriate cruciform's dimensions elaborated with the use of Finite Element Method (FEM). Similar solution was introduced by Creuziger et al. [10], who was able to achieve a crack in the sample centre. However, the milling process in this case has an influence on the material characteristics.
An innovative sample's shape was proposed by Karadogan et al. [11]. The centre of the sample was also milled, but contrary to Shao's idea, prominent results were achieved without the slits on the cruciform arms. It was feasible by devising a defined area in which the thickness of the specimen was reduced. What is more, the regions subjected to multi-type plane stress states were discovered. Different sample configurations were examined by Song et al. [12] - one-stage or two-stage thickness reduction of the cruciform centre, slits on arms or their absence. By two stage milling of the sample gauge region, $9 \%$ of strain was reached. The Authors implemented an interesting methodology of defining the material forming limit strain at the fracture. The method consists in the observation of strain-rate increase and was described in their previous work [13]. Just before a fracture, a sudden strain-rate boost can be observed.

Similarly to other authors, in order to concentrate plastic deformations in the central part of the cruciform, thinning of the sample's centre was used by Baptista et al. [14]. Two objective functions, namely: the maximal deformations in the required area and the uniformity of the relative deformation distribution, were used in the optimization. The established optimization area was relatively small, what significantly limited the possibilities of the results assessment. Smits et al. [15] have also contributed to the issue by the work which employed FEM to analyse the different shapes of samples, including the milling 
of the central region. Afterwards, Digital Image Correlation (DIC) method was used, enabling the evaluation of the strains during experimental conditions in a reliable way.

Hou at al. [16] developed a new method to strengthen the arms of ISO Standard cruciform specimen in order to increase plastic deformation in the desired region. The strength of the arms of cruciform sample was enhanced by a laser deposition of thickening layers using materials compatible with the base metal. The obtained plastic deformation was reported to be as high as $11 \%$. An optimized cruciform sample geometry to determine the yield surfaces was proposed by Nasdala at al. [17]. The authors optimized the size of the slits, filet radius and the thickness of the gauge area. The obtained ratio between the maximum equivalent strains and the fracture strain was around $66 \%$ which is about 2.5 times higher as compared to the specimen shape designed according to the ISO 16842 standard.

Upadhyay at al. [18] presented an approach to define the influence of different cruciform shape parameters on the strains reached during the bi-axial stretching. The researchers used FEM analysis to verify six different cruciform specimen shapes. Based on the results they provided a guidelines to design a good cruciform sample: symmetric along all three directions, size of slit-widths similar to the gauge region thickness, sufficiently thin gauge area thickness to concentrate strains in the specimen centre. The general overview of the influence of the specimen's shape on the strains in the central zone of the sample was presented by Lamkanfi et al. [19]. A generic approach with only four parameters was used. According to the suggestion, cruciforms should have only one curvature. Another outcome of the work suggests that the best specimen's shape should have one big inner radius on the arms. The importance of interaction between sample's arms and the way, how the load from the equipment is introduced into the specimen was underlined. What is more, the significance of minor changes in the cruciform's design was confirmed.

The noticeable dependence between the stress uniformity and the proper shape of the sample was indicated by Hanabusa et al. [20]. The paper presents the guidelines for choosing the size of the gauge area in order to increase the accuracy of the measurement. Another FEM simulations in search of the adequate geometry of the cruciform have led Liu et al. [21]. Different solutions like: notches and radius to decrease the strains in the corners and thickness reduction to increase the values of strains in the centre, have been compared in the paper. An original guidance for designing the cruciform shape to increase the plastic strain in the centre was elaborated by Song et al. [12]. According to the Authors, the sample should have tapered arms, deep notches and reduced thickness in the central zone. Uniformity of strains in the central zone is also desirable and can be boosted effectively by forming slots in the arms. Moreover, Pereira at al. [22] indicated that in order to avoid an occurrence of shearing stresses in the cruciform sample which can significantly influence the results, it is necessary to ensure the correct position of the grips, guaranteeing the specimen's centering before starting the experimental procedure.

As presented above, there are multiple attempts to achieve the highest strains in the gauge area, but still there is a lot of work to be done to improve the shape of cruciform samples for the biaxial tensile testing.

Therefore, the aim of the paper is to use the interesting specimen shape comparison methodology presented by Makris et al. [23] for a wide variety of samples geometry, chosen based on the literature research. As suggested by Liu et al. [21] the work was carried out on flat specimens to avoid the unfavourable influence of the milling process of the measurement area. Two types of samples were chosen according to Lamkanfi et al. [19] - sample with two curvatures, denoted as sample $\mathrm{C}$ in our specimens tests group and sample D which was characterized by one big inner radius on the arms. Based on the work of Song et al. [12] samples D, E and G had tapered arms, however slots and milling of the central region were abandoned since those treatments modify the properties of the material and disturb the reliability of the results. Dimensions of the measurement region were adopted on the basis of work of Hanabusa et al. [20]. The comparison method was implemented using the factors allowing the evaluation of the results of simulations for different samples and to find the one the matches the requirements in terms of the highest level of strain in the gauge region. The work includes the elaboration of specimen's digital models employing FEM as well as an experimental validation with DIC method on a tests stand for each specimen's geometry. 


\section{SIMULATION}

\section{Comparison methodology}

In order to compare samples, a series of equations were used to derive factors enabling the comparison. The factor should indicate whether the sample is better or worse than the other. Therefore the samples were divided in two regions. In the centre of the sample a gauge region was chosen, defined as a circle of $25 \mathrm{~mm}$ diameter and it was called the "Section A". The region outside the Section A was called "Section B". According to Makris et al. [23], two factors were introduced which later were combined into one main factor.

$$
F R=\frac{\varepsilon_{\max , B}}{\varepsilon_{\max , A}}
$$

First equation (1) that was used, is called Failure Ratio $(F R)$ and it defines the ratio between the maximum plastic strain in section $\mathrm{B}\left(\varepsilon_{\max , B}\right)$ to section $\mathrm{A}\left(\varepsilon_{\max , A}\right)$. The minimisation of this object function $F R$ can lead to an optimised shape concerning damage initiation-concentration in the centre of the specimen.

$$
\operatorname{COV}=\frac{\operatorname{sd}\left(\varepsilon_{1 A}\right)}{\operatorname{mean}\left(\varepsilon_{1 A}\right)}
$$

Second equation (2) is the ratio between the standard deviation $s d\left(\varepsilon_{1 A}\right)$ and the mean value mean $\left(\varepsilon_{1 A}\right)$ of the major strain in the centre of the sample, called Coefficient of Variation (COV) in the section A. The location and number of points taken into account to calculate above parameters were determined from the FEM's grid. Therefore, all mesh points inside the A section were considered. The $\mathrm{COV}$ parameter defines how uniform is the strain inside the centre of the sample. The uniformity of strain in the centre region is not related to fracture of the specimen but it defines the quality of biaxial testing.

$$
C F=\frac{1}{w f \frac{F R_{\min , i}}{F R}+(1-w f) \frac{C O V_{\min , i}}{C O V}}
$$

The third equation [23] allows to compare all samples taking into account both previously introduced factors: $F R$ and $\mathrm{COV}$. This equation is called the Cost Function $(C F)$ and it uses wf coefficient which indicates, which of the first two coefficients is more important. According to Makris et al. [23], the coefficient was equal to 0.8 , which means that $F R$ coefficient was 4 times more important than the $C O V$. Finally, the $C F$ was used to derive the best samples out of all tested ones.

\section{Samples geometry and model}

The nominal dimensions of the samples are presented in Figure 2. Because of the test stand geometry, the main boundary condition for their design is clamping position and dimensions as presented in Fig. 3 (red ellipse).

All the samples were prepared in ANSYS modelling software as one body with two parts, where one part was the centre of the sample (circle of $25 \mathrm{~mm}$ in diameter) and the second was the rest of the specimen. Also, each sample was prepared as $1 / 4$ of the geometry and later full geometry was created with pattern function. The thickness of all samples was $0.5 \mathrm{~mm}$.

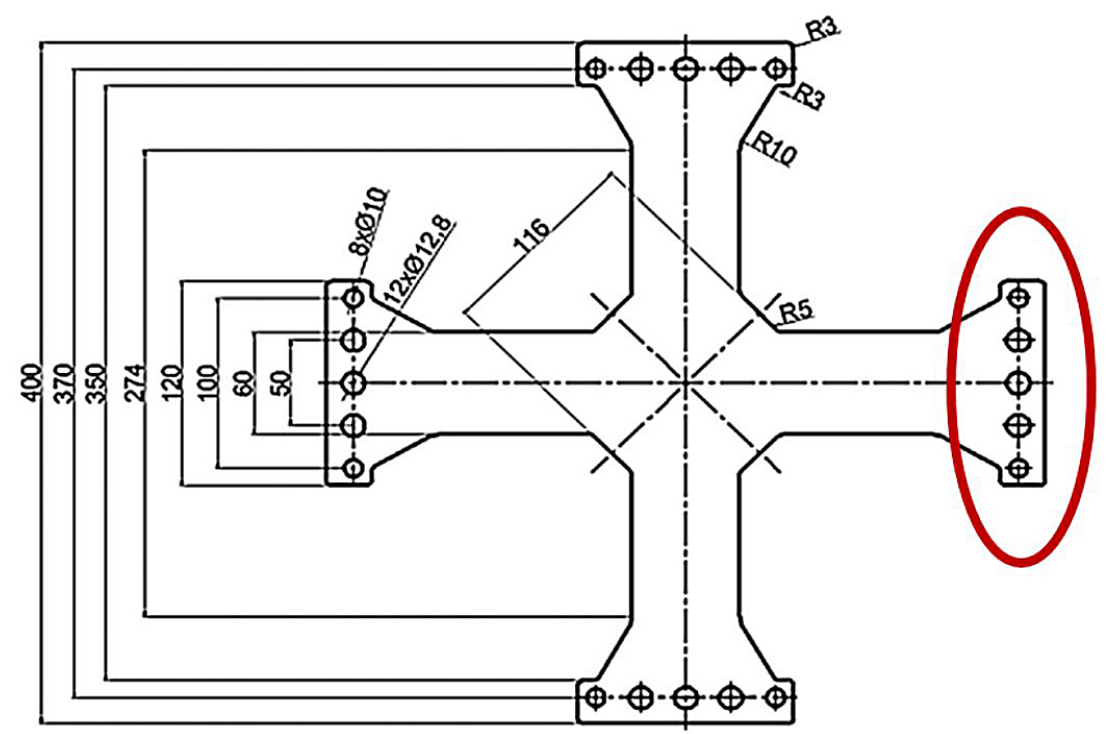

Fig. 2. Geometry requirements for samples to fit in to test stand [24] 


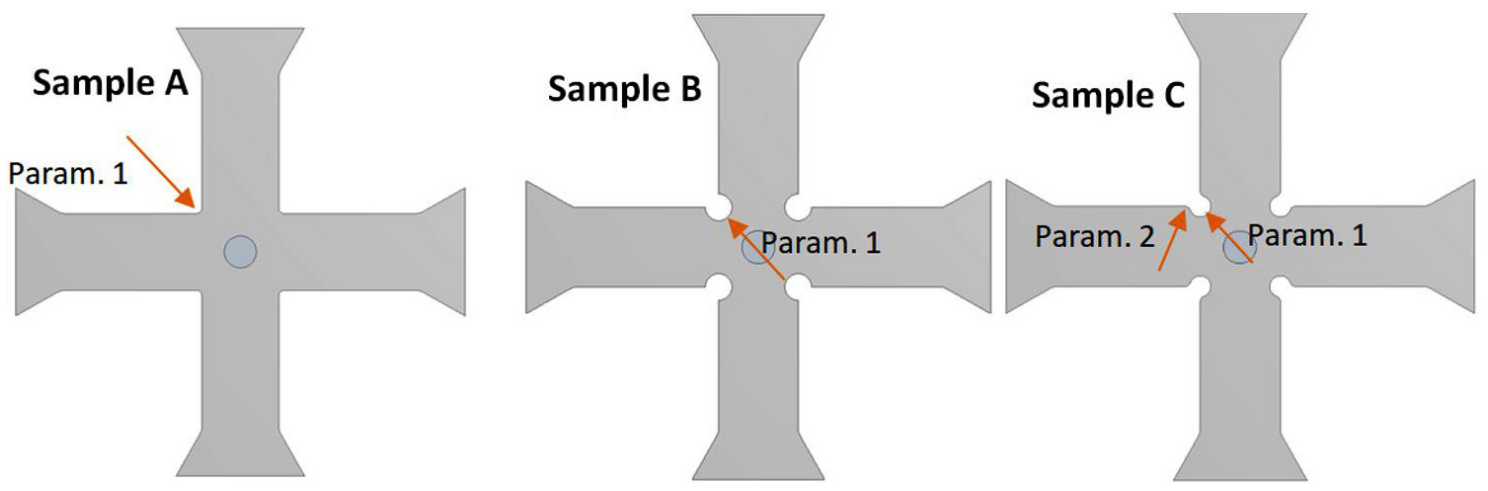

Fig. 3. Group of geometries with straight arms

First group of the prepared cruciform samples were those with straight arms as presented in Figure 3. Sample A is the sample where the radius was the investigated parameter in the range from $4 \mathrm{~mm}$ to $20 \mathrm{~mm}$ with an increment of $2 \mathrm{~mm}$. In Sample B, the radius of the circular cut-out was the analysed parameter in range from $1 \mathrm{~mm}$ to 19 $\mathrm{mm}$ with an increment of $1 \mathrm{~mm}$. Sample $C$ is very similar to Sample B, the parameter 1 in both cases is the same, but there is also an additional second radius (Param. 2). The Param. 1 was analysed from $4 \mathrm{~mm}$ to $14 \mathrm{~mm}$ with an increment of $2 \mathrm{~mm}$, while Param. 2 was investigated in range from 4 $\mathrm{mm}$ to $12 \mathrm{~mm}$ with an increment of $2 \mathrm{~mm}$.

Second group of samples that were created were the samples with the curved arms as presented in Figure 4. Samples D - F were created with the use of spline which was based on five points: two points at the ends of the arms (red), one point close to the centre on the symmetry line (red) between two arms and other two points of which position coordinates were parametrized (orange). However, in Sample D, the curvature is on the whole arm while in Samples $\mathrm{E}$ and $\mathrm{F}$, the curvature starts at $50 \mathrm{~mm}$ and $70 \mathrm{~mm}$

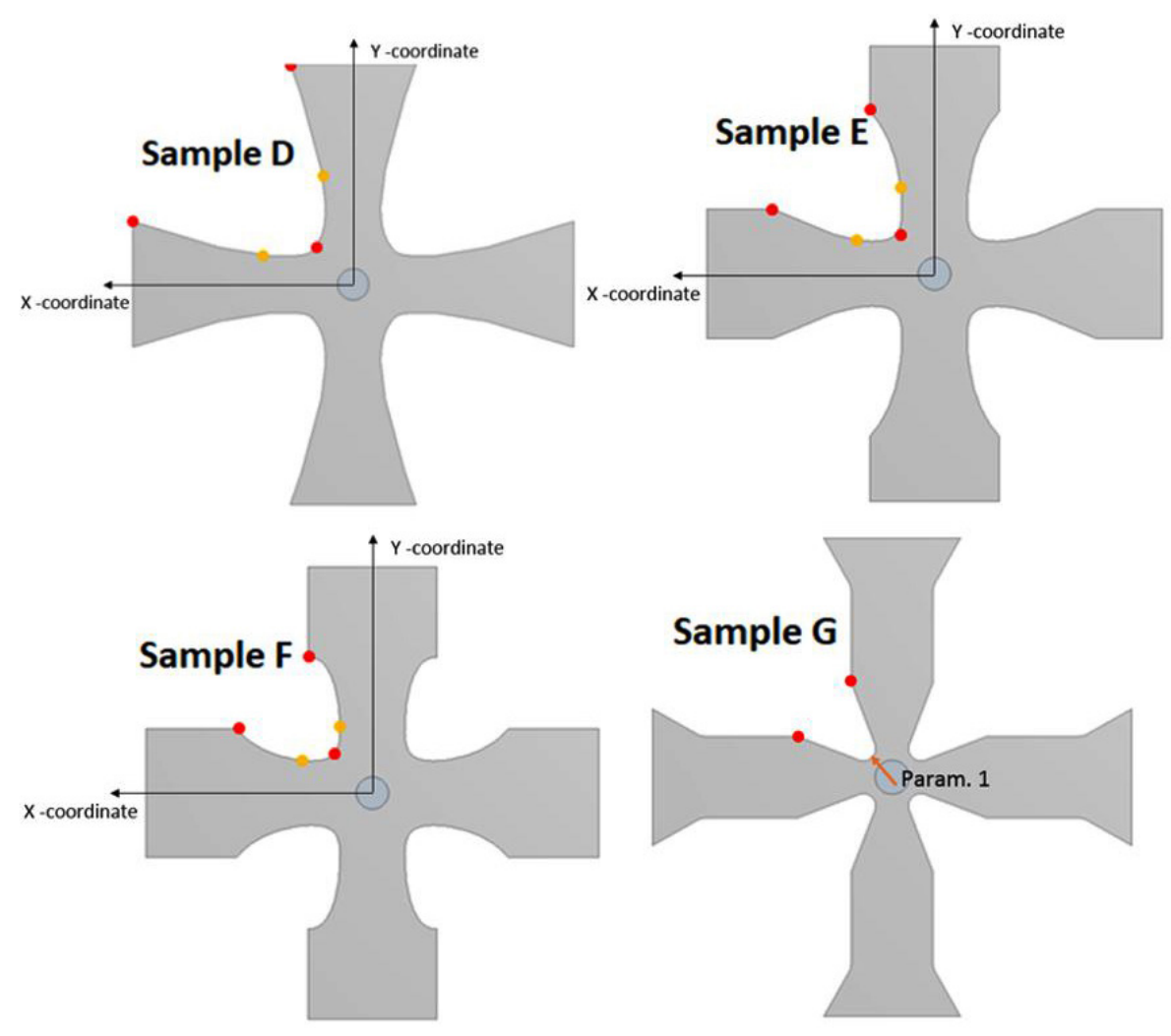

Fig. 4. Group of geometries with curved arms 
Table 1. Ranges of coordinates that were analysed for Samples D - F

\begin{tabular}{|l|c|c|c|}
\hline \multicolumn{1}{|c|}{ Specification } & Sample D & Sample E & Sample F \\
\hline X coordinate range $(\mathrm{mm})$ & $50-70$ & $50-70$ & $50-70$ \\
\hline Increment $(\mathrm{X})(\mathrm{mm})$ & 5 & 5 & 5 \\
\hline Y coordinate range $(\mathrm{mm})$ & $15-25$ & $15-25$ & $15-25$ \\
\hline Increment $(\mathrm{Y})(\mathrm{mm})$ & 2.5 & 2.5 & 2.5 \\
\hline
\end{tabular}

from its end, respectively. Values of the coordinates and the increment can be seen in Table 1 .

Sample G was created on the basis of the two lines at an angle to the arms connected with the radius, which was a parameter. What is more, the lower parameter, the closer cut-out was approaching the centre of the sample. The values of radius were analysed in the range from $1 \mathrm{~mm}$ to $10 \mathrm{~mm}$ with an increment of $1 \mathrm{~mm}$. In order to have a

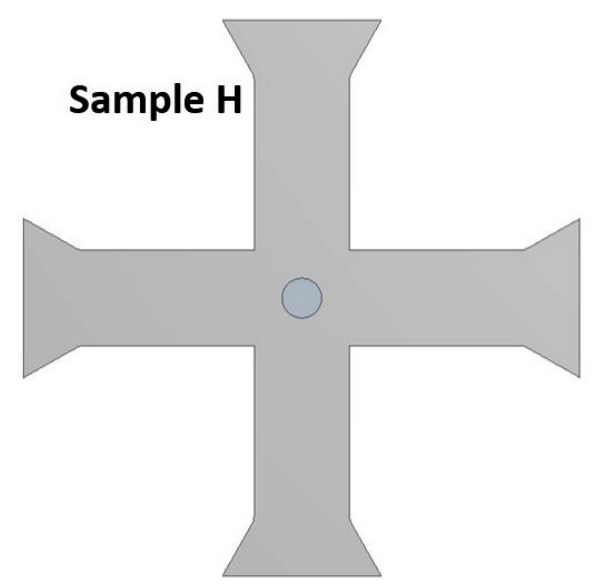

Fig. 5. Sample with no arms refinement (reference geometry) reference for the $C F$ coefficient, the geometry $\mathrm{H}$ was created, which can be seen in Figure 5. It has no refinement of the arms so its $C F$ coefficient should approach the highest value out of all simulations as it was later validated.

\section{Materials}

Steel sheets $(0.5 \mathrm{~mm}$ thick $)$ of cold-rolled DC5 (1.0312, EN10139; C $\leq 0.06 ; \mathrm{Mn} \leq 0.35 ; \mathrm{P}$ $\leq 0.025 ; \mathrm{S} \leq 0.025)$ were used in the experiment. The mechanical characteristics (Table 2), including proof stress at $0.2 \%$, plastic strain (Rp0.2), ultimate stress $(\mathrm{Rm})$, maximum force (Fm), uniform elongation $(\mathrm{Ag})$ and strain at rupture with $80 \mathrm{~mm}$ gauge length (A80), were tested using the Zwick/Roell tensile test machine according to DIN EN ISO 6891-1/ISO 10113. The true strain and true stress which were used as input data to describe strain hardening behaviour of the material were calculated according to the formulas:

- True stress

$$
\sigma_{T}=\sigma(1+\varepsilon)
$$

- True strain $\varepsilon_{T}=\ln (1+\varepsilon)$

where: $\sigma$ and $\varepsilon$ are engineering stress and engineering strain respectively.

The stress strain curves are shown in Figure 6.

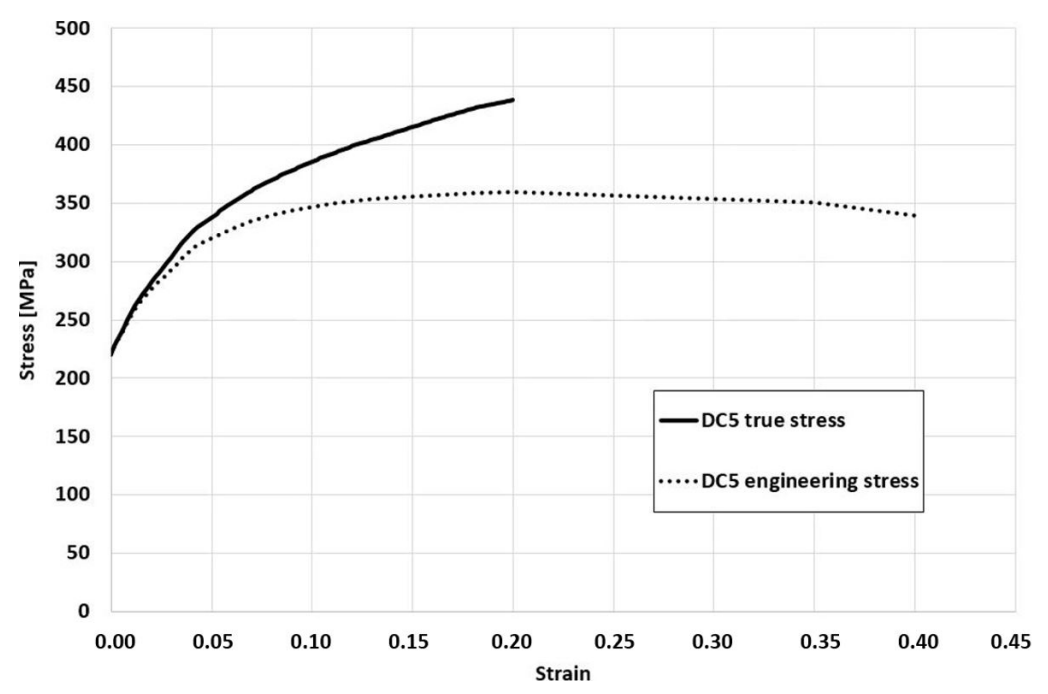

Fig. 6. DC5 steel stress strain curves 
Table 2. Mechanical parameters of DC5 steel determined based on static tensile test

\begin{tabular}{|c|c|c|c|c|}
\hline $\begin{array}{c}\mathrm{R}_{\mathrm{p} 0.2} \\
\mathrm{MPa}\end{array}$ & $\begin{array}{c}\mathrm{R}_{\mathrm{m}} \\
\mathrm{MPa}\end{array}$ & $\begin{array}{c}\mathrm{F}_{\mathrm{m}} \\
\mathrm{kN}\end{array}$ & $\begin{array}{c}\mathrm{A}_{\mathrm{g}} \\
\%\end{array}$ & $\begin{array}{c}\mathrm{A}_{80} \\
\%\end{array}$ \\
\hline 220 & 360 & 3.83 & 20.01 & 42.6 \\
\hline
\end{tabular}

\section{Mesh}

The specimen in the FE model was meshed by 8 -nodes hexahedral elements. The mesh convergence study was done starting with the default meshing configuration and finishing with the global mesh size lower than $2 \mathrm{~mm}$, subsequently refined for central part of the sample. The mesh seed of the circle which is a contact point between section A and Section B was set to 80 divisions for both parts. The skewness in all simulations was below 0.9 which is in a range of good and the aspect ratio was no larger than 4 which is also an indication of a good mesh quality. The boundary conditions imitated the equal displacement of the 4 jaws with a constant speed set up to $1 \mathrm{~mm} / \mathrm{s}$. The simulation time was set up to 10 seconds what results in $10 \mathrm{~mm}$ displacement of each jaw.

\section{Samples selection}

Based on the $C F$ coefficient, several dependencies were found, which indicate the optimal geometries for cruciform samples. Figure 7 presents the dependency between the radius between the arms and the $C F$ coefficient of Sample A. It can be observed, that according to the simulated configurations the minimum $C F$ coefficient was obtained for radius of $10 \mathrm{~mm}$, which suggests that this value may work best out of all simulated ones.
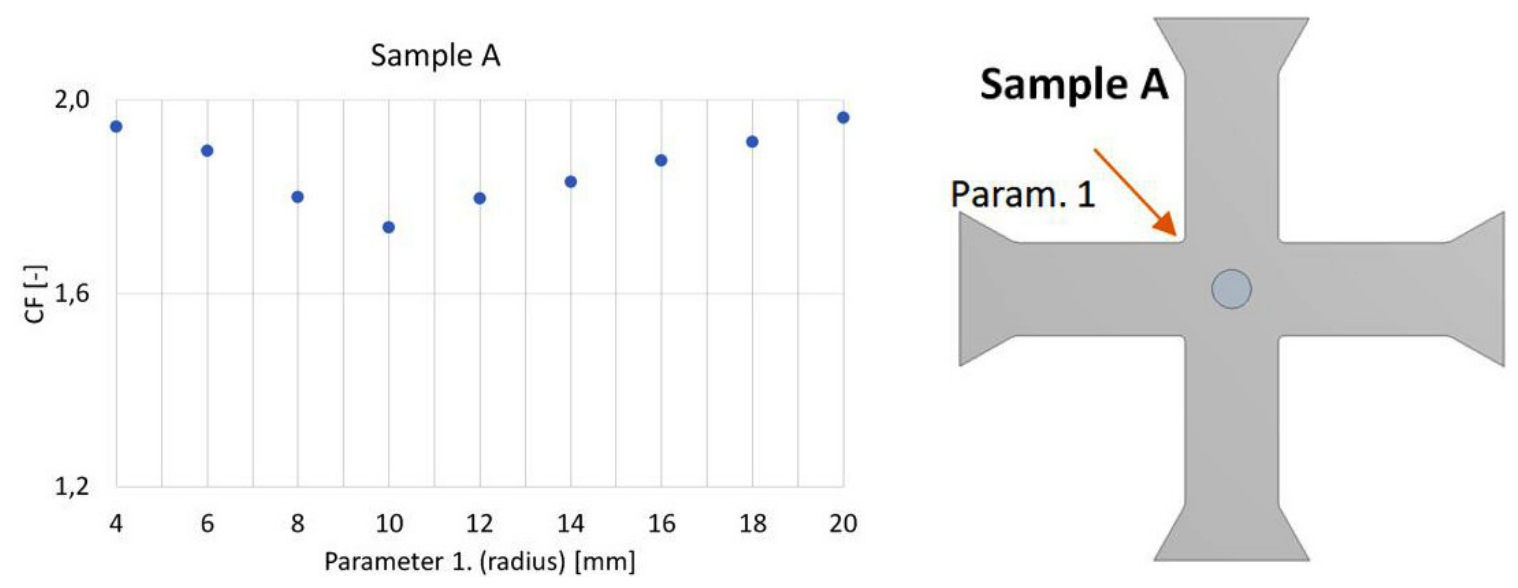

Fig. 7. The influence of parameter 1 on the Cost Function for Sample A
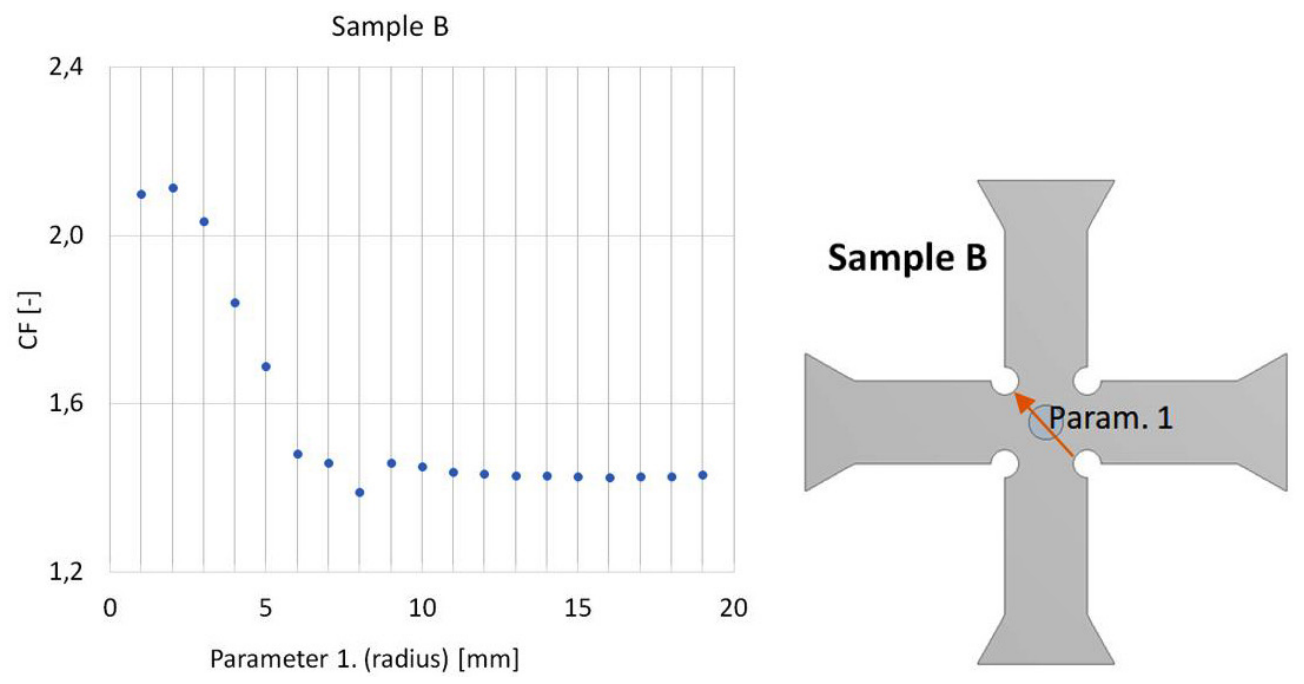

Fig. 8. The influence of parameter 1 on the Cost Function for Sample B 
Figure 8 presents the dependency between the radius of the cut-out between the arms and the $C F$ coefficient for Sample B. It can be noticed, that the further increase in the radius of the cut-out does not influence the $C F$ coefficient for values higher than $10 \mathrm{~mm}$. This suggests that the sample performance is not changing as soon as the cutout radius reaches ca. $10 \mathrm{~mm}$.

Figure 9 presents the influence of the radius of the cut-out between the arms (called inner radius or parameter 1) for five different outer radii (parameter 2) on the $C F$ coefficient for Sample C. It can be noticed that the influence of the outer radius is negligible. Therefore the effects are similar to the results obtained for Sample B.

Figure 10 depicts the dependency of the $\mathrm{X}$-coordinate for seven different $\mathrm{Y}$-coordinates with reference to the $C F$ coefficient. It can be noticed, that the lowest value was obtained for the $\mathrm{X}$ - coordinate equal to $65 \mathrm{~mm}$ and $\mathrm{Y}$ - coordinate of $20 \mathrm{~mm}$.
Figure 11 depicts the dependency of the Xcoordinate for five different Y-coordinates with reference to $C F$ coefficient. It can be seen that the lowest value was obtained for the $\mathrm{X}$ - coordinate equal to $22.5 \mathrm{~mm}$ and $\mathrm{Y}$ - coordinate of $70 \mathrm{~mm}$.

Figure 12 shows the dependency of the Xcoordinate for five different Y-coordinates with reference to $C F$ coefficient. It can be seen that the lowest value was obtained for the $\mathrm{X}$ - coordinate of $22.5 \mathrm{~mm}$ and $\mathrm{Y}$ - coordinate equal to $70 \mathrm{~mm}$.

Figure 13 presents the dependency between the radius between the arms and $C F$ coefficient in Sample G. It can be observed that according to simulated configurations, at the radius of $10 \mathrm{~mm}$ the minimum $C F$ coefficient was obtained.

\section{TEST STAND}

Laboratory experiments were conducted in order to verify the results of simulations. The
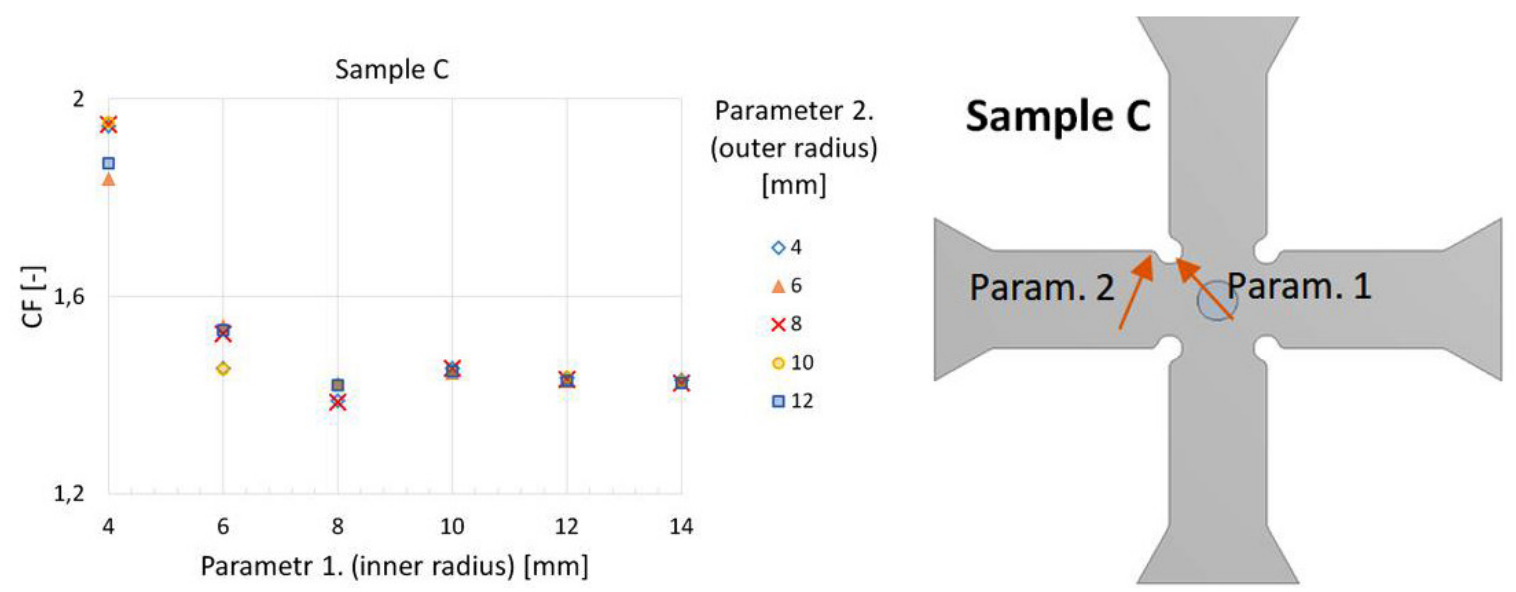

Fig. 9. The influence of parameters 1 and 2 on the Cost Function for Sample C

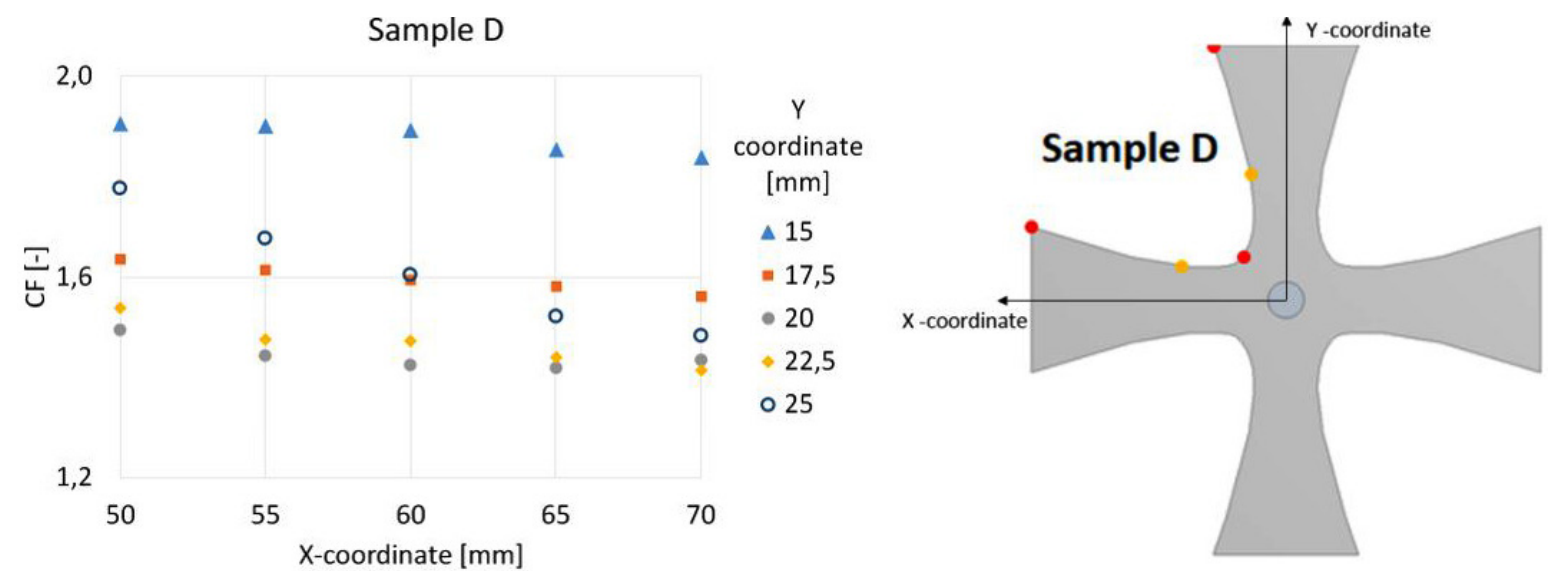

Fig. 10. The influence of the coordinates $X$ and $Y$ on the Cost Function for sample D 

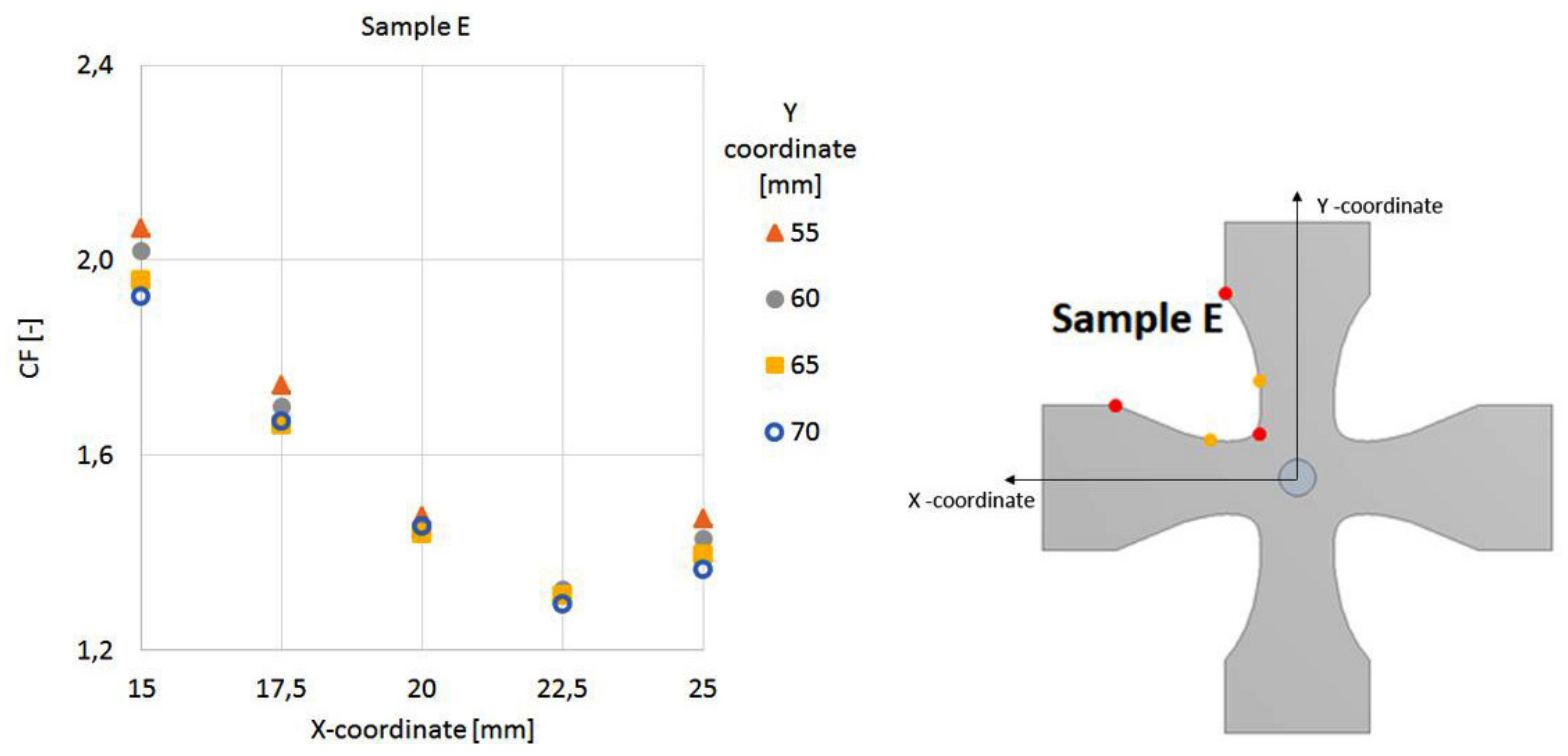

Fig. 11. The influence of the coordinates $\mathrm{X}$ and $\mathrm{Y}$ on the Cost Function for sample $\mathrm{E}$
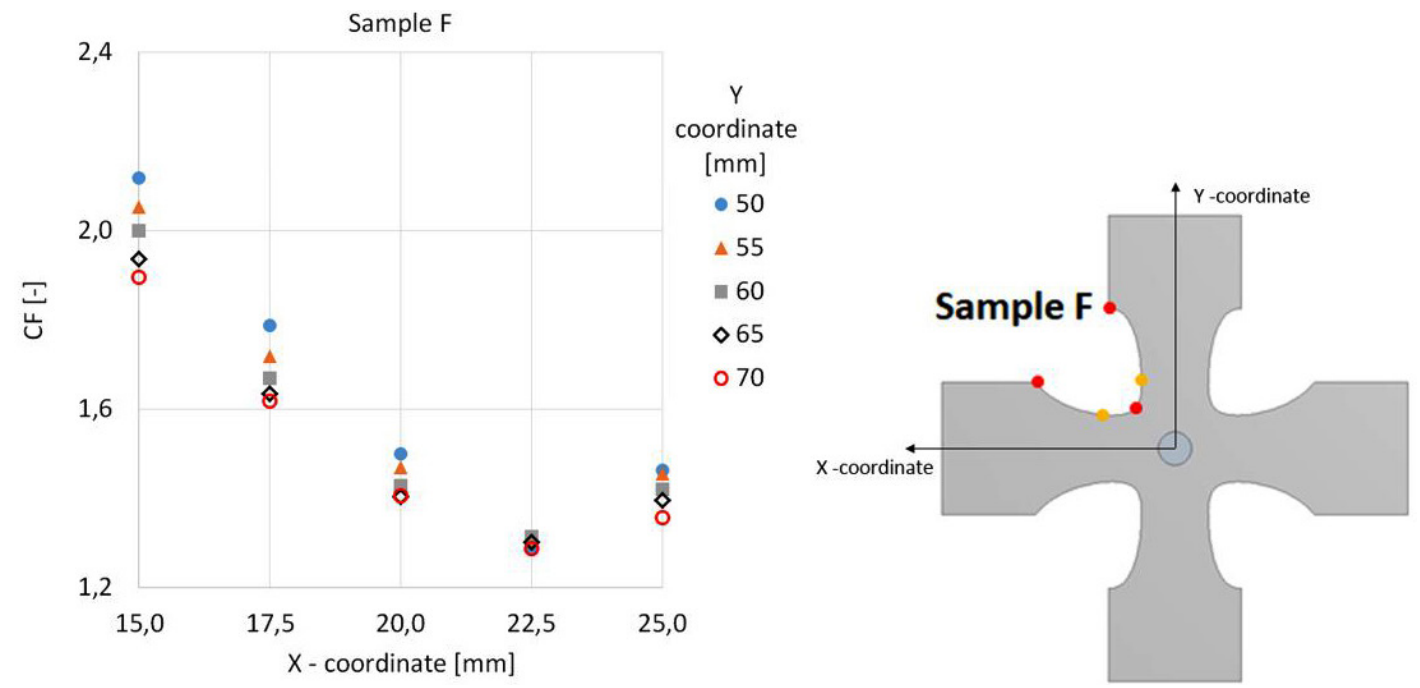

Fig. 12. The influence of the coordinates $\mathrm{X}$ and $\mathrm{Y}$ on the Cost Function for sample $\mathrm{F}$

samples were cut from $0.5 \mathrm{~mm}$ thick S235JR steel sheet using the waterjet technique. The test stand consists of the two round steel plates as presented in the Figure 14. The sample is put in four jaws, where it is clamped and deformed by the small shaft to create the shape connection, preventing it from slipping during the test. Above the test stand, there is a camera placed perpendicularly on the tripod in order to take pictures after each small stretching motion. A measuring system has been described in previous work - Mitukiewicz et al. [25]. The ratio between millimetres and pixels was $1 \mathrm{~mm} / 20 \mathrm{px}$. The gauge length corresponded to ten grids. Since the size of one grid was $2 \mathrm{~mm}$ the gauge length was (400 px \pm 2 pixel), the expected uncertainty for each data point was less than $1 \%$ of strain.

The test was carried out for equi-biaxial tensile state. The displacement of each arm was driven by screw, which had a pitch of $1.5 \mathrm{~mm}$. The test was stopped, when there was no longer any elongation increase in the gauge region of the sample. Then the load was released and the achieved experimental plastic elongation was measured directly by a digital image correlation (DIC) system. The experimental plastic strain were calculated based on the obtained results. 

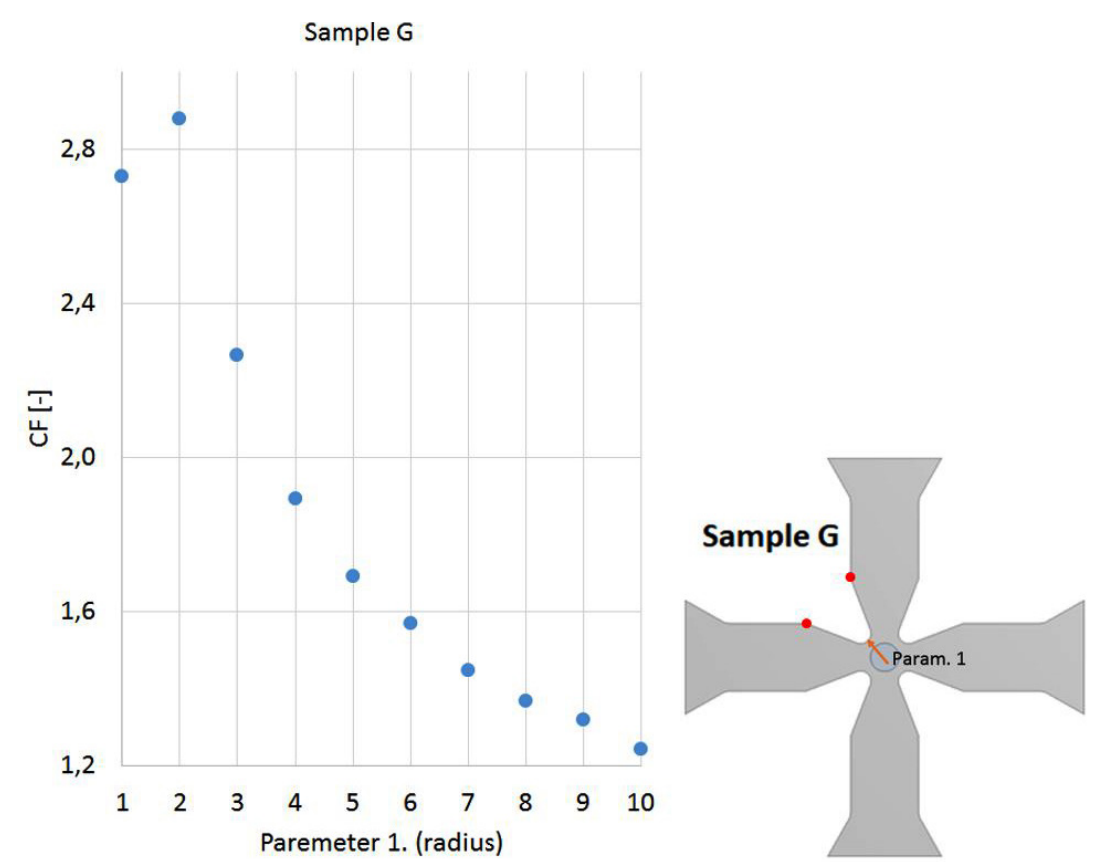

Fig. 13. The influence of parameter 1 on the Cost Function for Sample G

\section{RESULTS AND DISCUSSION}

After the series of multiple simulations, it was possible to select geometries, which should give the best results. There are 3 samples with curved arms (D, E, G) and 2 samples with straight arms (A, B). Each of them is rather unique. Figures 15 and 16 show plastic strain distribution of the chosen sample geometries.

Table 3 presents the results of the experiment for five chosen sample geometries. As can be seen, there is a good correlation between the simulations outcomes and the experimental results. In Table 3 the values of $C F$ are also indicated. As can be seen more clearly in the Figure 17, a)

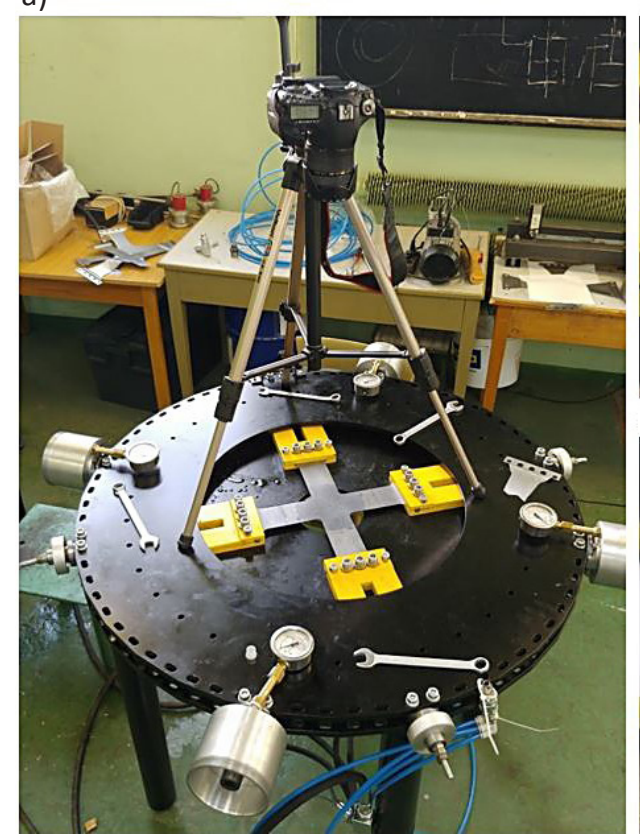

b)

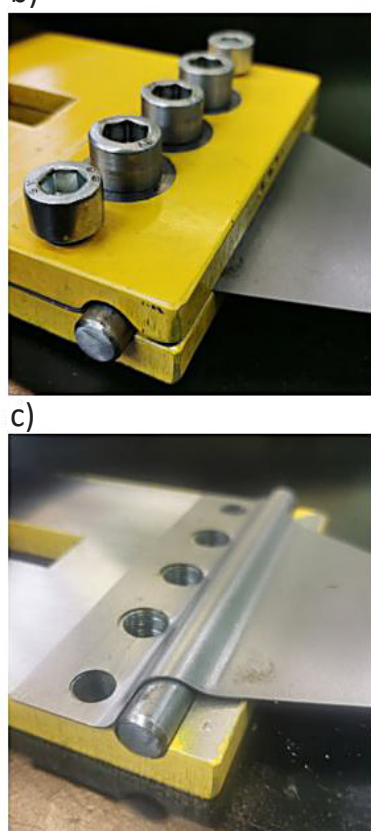

Fig. 14. a) experimental test stand, b) clamped sample, c) sample after test 

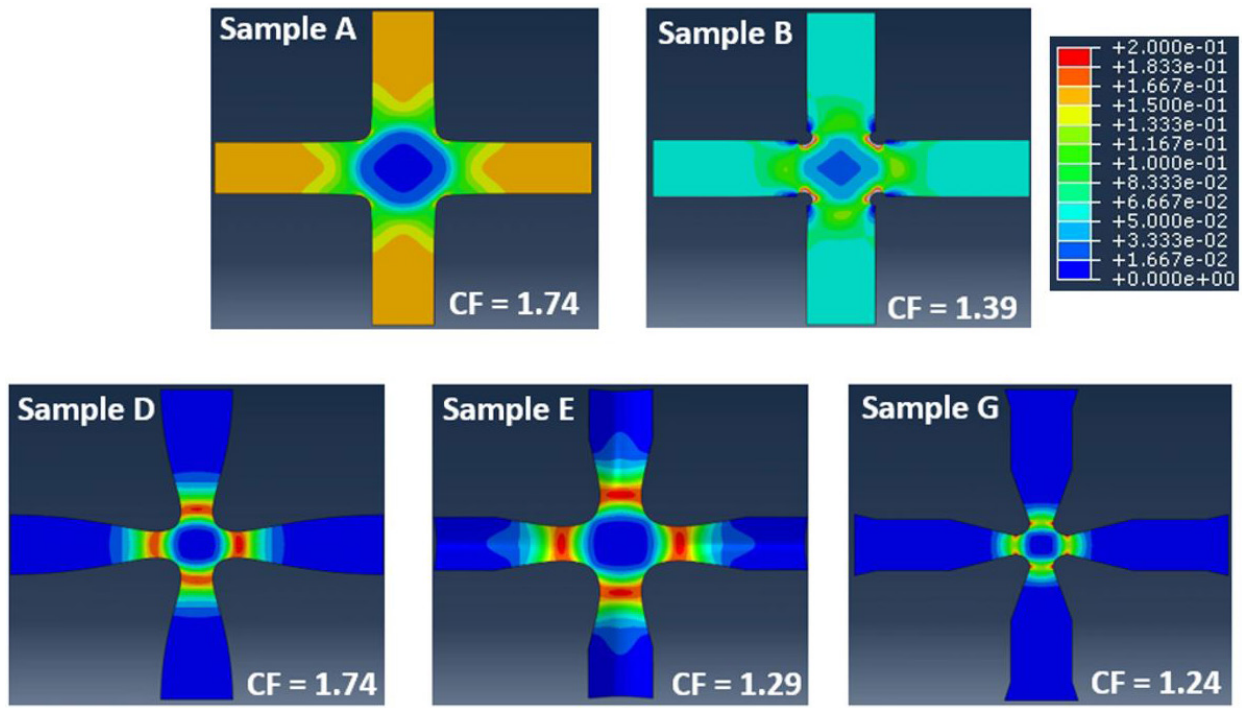

Fig. 15. Plastic strain distribution of the sample geometries selected based on FEM simulations and their $C F$ coefficients (scale from 0 to 0.2 )
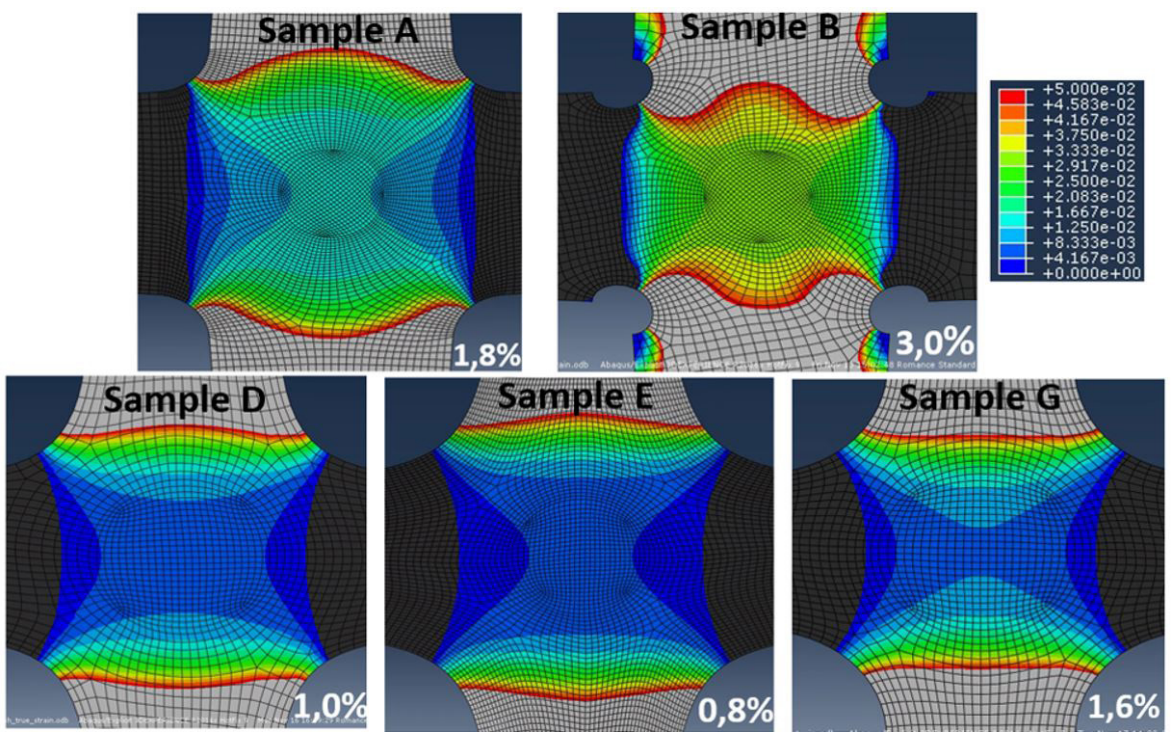

Fig. 16. Strain distribution of the sample geometries selected based on FEM simulations and their $C F$ coefficients (scale from 0 to 0.05 )

basing on the rule of Makris methodology, that the smaller value of $C F$, the bigger value of achieved strains, it is hard to conclude on the geometry of samples of different shapes. The $C F$ factor does not correspond with the values of engineering strains in global terms. Even if the sample A has a higher value of $C F$ coefficient (1.74) as compared to sample E (1.29) or G (1.24) it reaches higher strains in the gauge region. Similarly for sample B with $C F$ equal to 1.39 the obtained strains are higher than those for samples D, E, G with lower $C F$ factors. Therefore also in Table 3 and Figure
17 a new parameter is proposed. Relative Cost Function $(R C F)$ parameter is defined as follows:

$$
R C F=\frac{\varepsilon_{\max , A}}{\varepsilon_{\max }} \cdot 100 \%
$$

For steel S235JR $\varepsilon_{\max }$ equals to $20 \%$.

The proposed parameter is very useful since it provides an information, how far is the designed sample from the theoretical ideal situation when $\varepsilon_{\max }$ will be achieved in the middle of the cruciform. The results in Table 3 show that the sample $\mathrm{B}$ has the highest $R C F$ equal to $15 \%$ and sample $\mathrm{E}$ has the lowest $R C F$ equal to $4 \%$. The rest of 


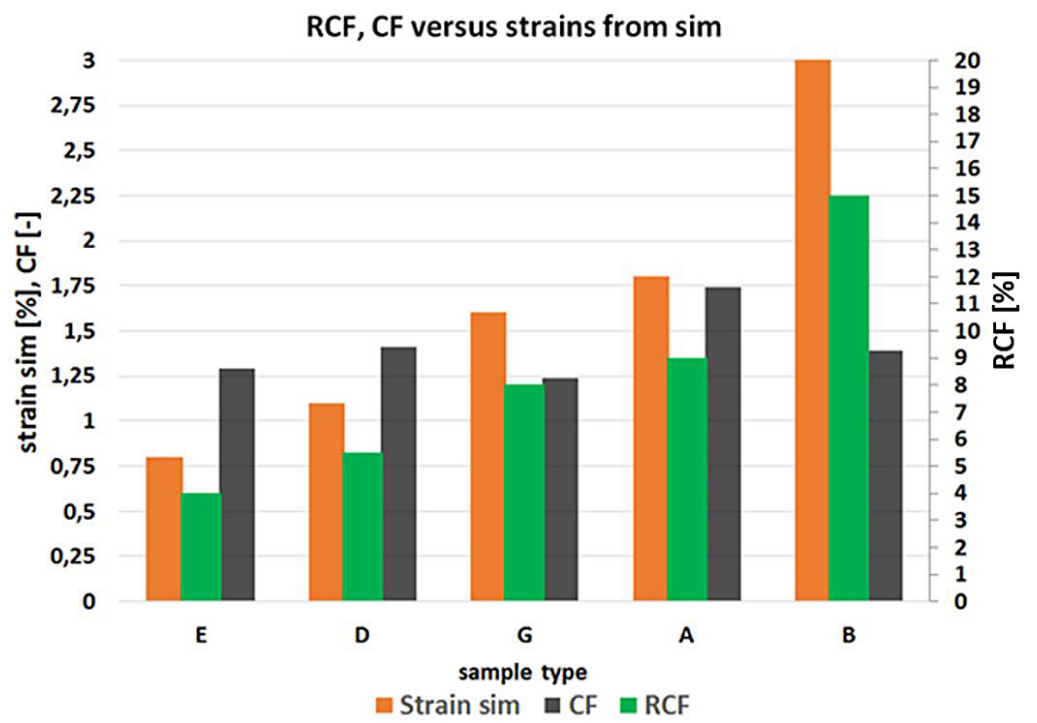

Fig. 17. Cost function versus experimentally obtained strain

Table 3. Test results

\begin{tabular}{|c|c|c|c|c|c|}
\hline Sample & G & E & B & D & A \\
\hline CF & 1.24 & 1.29 & 1.39 & 1.41 & 1.74 \\
\hline $\begin{array}{c}\text { Plastic strain } \\
\text { (\%) Simulation }\end{array}$ & 1.6 & 0.8 & 3.0 & 1.1 & 1.8 \\
\hline $\begin{array}{c}\text { Plastic } \\
\text { strain (\%) } \\
\text { Experiment }\end{array}$ & 2.0 & 0.5 & 3.0 & 1.5 & 2.0 \\
\hline RCF (\%) & 8 & 4 & 15 & 5.5 & 9 \\
\hline
\end{tabular}

the samples are between those values. We can observe as well that the values between strains obtained from the simulation and the strains registered during the experiment are very close.

The results show that the maximal strain obtained from the simulation is $3 \%$ for the sample B. The sample B also represents the highest $R C F$ equal to 15 percent. The graphical representation in Fig. 17 shows the order of the samples with increasing $R C F$ and increasing strains. So we can follow the effect of the RCF parameter on the mechanical characteristics of the samples.

\section{CONCLUSIONS}

The work summarized in this paper aimed to use one of the published specimen shape comparison methodology, to obtain the highest possible elongation in the centre of the sample for different types of specimens used in biaxial tensile tests. Our paper includes parametric simulation and comparison of multiple types of specimens shape with simultaneous wide experimental validation. Based on the obtained results it can be noticed that the initially introduced comparison coefficient do not match to the registered elongations along all test results. It is strongly believed that the initial $C F$ coefficient is sufficient to compare the geometry of one type of samples by changing only one parameter of the sample shape. The sample B is with the highest $R C F$ of $15 \%$ and sample $\mathrm{E}$ has the lowest $R C F$ of $4 \%$. For the global specimen shape optimisation a multi-criteria method should be used. A new parameter enabling a useful comparison of different shapes of cruciforms made of different materials in terms of obtaining large strain in the analysis of their plane stress state.

\section{Nomenclature}

\begin{tabular}{|l|l|c|}
\hline Symbol & \multicolumn{1}{|c|}{ Name } & Unit \\
\hline$C F$ & Cost Function coefficient & {$[-]$} \\
\hline$C O V$ & Coefficient of Variation & {$[-]$} \\
\hline$F R$ & Failure ratio coefficient & {$[-]$} \\
\hline$\varepsilon_{\max A \text { or } B}$ & Maximum plastic strain in region A or B & {$[-]$} \\
\hline$\varepsilon_{1 \text { A or } B}$ & Major plastic strain in region A or B & {$[-]$} \\
\hline$\varepsilon_{\max }$ & $\begin{array}{l}\text { Maximal accessible extension for particular } \\
\text { material (before the crack) }\end{array}$ & {$[-]$} \\
\hline mean & Mean value & {$[-]$} \\
\hline$s d$ & Standard deviation value & {$[-]$} \\
\hline$w f$ & Weight function coefficient & {$[-]$} \\
\hline$\sigma$ & Engineering stress & {$[\mathrm{MPa}]$} \\
\hline$\varepsilon$ & Engineering strain & {$[-]$} \\
\hline$\sigma_{T}$ & True stress & {$[\mathrm{MPa}]$} \\
\hline$\varepsilon_{T}$ & True strain & {$[-]$} \\
\hline RCF & Relative Cost Function & {$[\%]$} \\
\hline
\end{tabular}




\section{REFERENCES}

1. Rowe J. Advanced Materials in Automotive Engineering. Woodhead Publishing Limited; 2012.

2. Horvath C.D. Advanced steels for lightweight automotive structures. In Materials, Design and Manufacturing for Lightweight Vehicles. Woodhead Publishing Limited; 2010:35-78.

3. Rojek J., Lumelskyy D., Pęcherski R., Grosman F., Tkocz M., Chorzępa W. Forming limit curves for complex strain paths. Archives of Metallurgy and Materials. 2013;58(2):587-593.

4. Nakazima K., Kikuma T., Hasuka K. Study of the formability of steel sheets. Yamata Technical Report. 1968;264:8517-8530.

5. Hecker S. S., Simple technique for determining forming limit curves. Sheet Metal Industries. 1975;52:671-676.

6. Marciniak Z., Kuczyński K. Limit strains in the processes of stretch-forming sheet metal. International Journal of Mechanical Sciences. 1967;9(9):609-612.

7. Hsu E., Carsley J. E., Verma R. Development of Forming Limit Diagrams of Aluminum and Magnesium Sheet Alloys at Elevated Temperatures. Journal of Materials Engineering and Performance. 2008;17(3):288-296.

8. Leotoing L., Guines D., Zidane I., Ragneau E. Cruciform shape benefits for experimental and numerical evaluation of sheet metal formability. Journal of Materials Processing Technology. 2013;213:856-863.

9. Shao Z., Li N., Lin J. The optimisation of cruciform specimen for the formability evaluation of AA6082 under hot stamping conditions. Procedia Engineering. 2017;207:735-740.

10. Creuziger A., Iadicola M. A., Foecke T., Rust E., Banerjee D. Insights into Cruciform Sample Design. The Journal of The Minerals, Metals \& Materials Society. 2017;69:902-906.

11. Karadogan C., Emin Tamer M. A novel and simple cruciform specimen without slits on legs yet higher plastic strains in gauge. Procedía Engineering. 2017;207:1922-1927.

12. Song X., Leotoing L., Guines D., Ragneau E. Characterization of forming limits at fracture with an optimized cruciform specimen: Application to DP600 steel sheets. International Journal of Mechanical Sciences. 2017;126:35-43.

13. Song X., Leotoing L., Guines D., Ragneau E. Investigation of the forming limit strains at fracture of AA5086 sheets using an in-plane biaxial tensile test. Engineering Fracture Mechanics. 2016;163:130-140.

14. Baptista R., Claudio R. A., Reis L., Madeira J. F. A., Freitas M. Optimal Cruciform Specimen Design Using the Direct Multi-search Method and Design Variable Influence Study. Procedia Structural Integrity. 2017;5:659-666.

15. Smits A., Van Hemelrijck D., Philippidis T.P., Cardon A. Design of a cruciform specimen for biaxial testing of fibre reinforced composite laminates. Composites Science and Technology. 2006;66:964-975.

16. Hou Y., Min J., Lin J., Carsley J. E., Stoughton T. B. Cruciform specimen design for large plastic strain during biaxial tensile testing, Journal of Physics: Conference Series. 2018;1063.

17. Nasdala L., Husni A.H. Determination of Yield Surfaces in Accordance With ISO 16842 Using an Optimized Cruciform Test Specimen. Experimental Mechanics. 2020;60:815-832.

18. Upadhyay M.V., Panzner T., Van Petegem S., Van Swygenhoven H. Stresses and Strains in Cruciform Samples Deformed in Tension. Experimental Mechanics. 2017;57: 905-920.

19. Lamkanfi E., Van Paepegem W., Degrieck J. Shape optimization of a cruciform geometry for biaxial testing of polymers. Polymer Testing. 2015;41:7-16.

20. Hanabusa Y., Takizawa H., Kuwabara T. Numerical verification of biaxial tensile test method using a cruciform specimen. Journal of Materials Processing Technology. 2013;213:961-970.

21. Liu W., Guines D., Leotoing L., Ragneau E. Identification of sheet metal hardening for large strains with an in-plane biaxial tensile test and a dedicated cross specimen. International Journal of Mechanical Sciences. 2015;101-102:387-398.

22. Pereira A B., Fernandes F.A.O., de Morais A. B., Maio J. Biaxial Testing Machine: Development and Evaluation, MDPI Machines. 2020, 8(3).

23. Makris A., Vandebergh T., Ramault C., Van Hemelrijck D., Lamkanfi E., Van Paepegem W. Shape optimisation of a biaxially loaded cruciform specimen. Polymer Testing. 2010;29:216-223.

24. Mitukiewicz G., Głogowski M. Cruciform specimen to obtain higher plastic deformation in a gauge region. Journal of Materials Processing Technology. 2016;227:11-15.

25. Mitukiewicz G., Głogowski M., Stelmach J.; Leyko J.; Dimitrova Z.; Batory D. Strengthening of cruciform sample arms for large strains during biaxial stretching. Materials Today Communications. 2019;21:100692. 